\title{
Mestrado profissional em Ensino de Matemática: identificação de seus produtos educacionais
}

\section{Professional master's degree in Mathematics Teaching: identification of its educational products}

\section{Máster Profesional en Matemáticas Enseñanza: identificación de sus productos educativos}

Luiz Alberto Pilatti, doutor em Educação Física pela Universidade Estadual de Campinas (Unicamp), professor titular e vice-reitor da Universidade Tecnológica Federal do Paraná (UTFPR), Curitiba, PR, Brasil.E-mail: lapilatti@utfpr.edu.br.

Jaqueline de Morais Costa, doutoranda do Programa de PósGraduação em Ensino de Ciência e Tecnologia da Universidade Tecnológica Federal do Paraná (UTFPR) e coordenadora geral de Gestão Acadêmica do Centro de Ensino Superior de Campos Gerais, Ponta Grossa, PR, Brasil. E-mail: j.moraiscosta@hotmail.com.

Ana Cristina Schirlo, doutoranda e mestre em Ensino de Ciência e Tecnologia pela Universidade Tecnológica Federal do Paraná (UTFPR) e docente da Secretaria de Educação do Estado do Paraná, Ponta Grossa, PR, Brasil. E-mail: acschirlo@gmail.com.

Sani de Carvalho Rutz da Silva, doutora em Ciência dos Materiais pelo Instituto de Física, Instituto de Química e Escola de Engenharia Metalúrgica, da Universidade Federal do Rio Grande do Sul (UFGRS) e professora da Universidade Tecnológica Federal do Paraná (UTFPR), Ponta Grossa, PR, Brasil. E-mail: sanirutz@gmail.com.

Nilcéia Aparecida Maciel Pinheiro, doutora em Educação Científica e Tecnológica pela Universidade Federal de Santa Catarina (UFSC) e professora da Universidade Tecnológica Federal do Paraná (UTFPR), Ponta Grossa, PR, Brasil. E-mail: nilceiaamp@gmail.com. 
Antônio Carlos Frasson, doutor em Educação pela Universidade Metodista de Piracicaba e professor adjunto dos Programas de Pós-Graduação em Ensino de Ciência e Tecnologia (PPGECT) e Engenharia de Produção (PPGEP) da Universidade Tecnológica Federal do Paraná (UTFPR), Ponta Grossa, PR, Brasil. E-mail: acfrasson@utfpr.edu.br.

\section{Resumo}

O presente estudo tem como objetivo identificar os produtos educacionais desenvolvidos nos programas de pós-graduação stricto sensu, modalidade mestrado profissional, na área de Ensino, que tenham como foco principal ou como linha de pesquisa o Ensino de Matemática. Os produtos educacionais coletados foram os disponiveis nos sítios dos programas de mestrado profissional, no período entre 2004 e meados de 2014. Os itens foram analisados e categorizados. Verificou-se uma concentração de produtos educacionais nas categorias de propostas de atividades, manual e livro. Concluiu-se que, apesar da reconhecida relevância dos produtos desenvolvidos nos programas de mestrado profissional na área de Ensino de Matemática, há limitada diversidade nos produtos desenvolvidos, além de fragilidade nas estratégias de difusão dos mesmos.

Palavras-chave: Mestrado Profissional. Produtos Educacionais. Área de Ensino.

\section{Abstract}

This study aims to identify educational products developed in strict sensu graduate programs, professional master mode, in the education area, where the primary focus is a line of research in the Teaching of Mathematics. Educational products collected were available on the websites of professional master's programs in the period between 2004 and mid-2014 when the items were analyzed and categorized. There was a concentration of educational products in the categories 
of proposed activities, manual and book. It was concluded that despite the recognized importance of products developed in the professional master's programs in the Mathematics Teaching area, there is limited diversity in the developed products, as well as a weakness in the dissemination strategies for the same.

Keywords: Professional Master. Educational Products. Education Area.

\section{Resumen}

Este estudio tiene como objetivo identificar los productos educativos desarrollados en programas de postgrado stricto sensu, modo maestro profesional, en el área de la educación, donde el objetivo principal o como una línea de investigación de la Enseñanza de las Matemáticas. Productos educativos recogidos estaban disponibles en los sitios web de los programas de maestría profesional en el período entre 2004 y mediados de 2014 los artículos fueron analizados y categorizados. Había una concentración de productos educativos en las categorías de actividades propuestas, manual y libro. Se concluyó que a pesar de la reconocida importancia de los productos desarrollados en los programas de maestría profesional en el área de enseñanza de las matemáticas, hay diversidad limitada en los productos desarrollados, así como la debilidad de las estrategias de difusión de la misma.

Palabras clave: Máster Profesional. Productos Educativos. Área de Educación.

\section{Introdução}

A educação brasileira, mesmo com diferentes rankings internacionais apontando para um quadro crítico, apresenta avanços recentes que não podem ser desconsiderados. A educação tradicional, moldada naquilo que Freire (2005) chamou de "modelo bancário", vem sistematicamente sendo superada, pois está vigente um ousado Plano Nacional de Educação (PNE), a ser cumprido no período compreendido 
entre 2011-2020, um plano que, na tentativa de eliminar desigualdades históricas existentes no país, tem como um dos seus objetivos constituir formas colaborativas mais orgânicas entre os sistemas de ensino (BRASIL, 2014). A aproximação da educação básica com o sistema de pós-graduação é um dos mecanismos que permitem perspectivar um devir alentador (CAPES, 2015a).

Nesse cenário que está sendo redesenhado, o mestrado profissional qualifica diferentes tipos de profissionais na aplicação do conhecimento adquirido na academia, em suas empresas, instituições públicas e particulares de ensino e de saúde e comunidades, entre outras, vinculando e ampliando os laços entre a universidade e a sociedade (FISCHER, 2005).

No ano de 2005, após o Seminário "Para além da academia - a pós-graduação contribuindo para a sociedade", realizado com a participação de representantes de todas das áreas do conhecimento, Ribeiro (2005) afirmou textualmente que os mestrados profissionais eram uma aposta da Coordenação de Aperfeiçoamento de Pessoal de Nível Superior (Capes), ou seja, uma política de governo em curso.

Corroborando Ribeiro (2005), Moreira e Nardi (2009) salientam que o mestrado profissional visa propiciar ao mestrando a imersão na pesquisa, porém, com o objetivo principal de formar um profissional que, no mundo do trabalho, saiba localizar, reconhecer, identificar e, sobretudo, utilizar a pesquisa de modo a agregar valor a suas atividades, sejam elas de interesse pessoal ou social.

Com natureza distinta, os mestrados profissionais na área de Ensino, particularmente amoldados na política de governo vigente, requerem do mestrando um trabalho de conclusão de curso distinto do exigido nos mestrados acadêmicos e, adicionalmente, a elaboração de um produto educacional.

Por meio do Google Acadêmico, utilizando os termos "produto educacional", "mestrado profissional" e "Ensino de Matemática”, na base SciELO, foram identificados 30 trabalhos publicados em diferentes 
periódicos. Analisando esses trabalhos, constatou-se, majoritariamente, a divulgação de produtos educacionais. Nenhum trabalho publicado apresentou a conotação de mapeamento da área.

Compreender esse cenário novo, que, na condição de política de governo, tem pouco mais de uma década, é necessário. O presente estudo lança um olhar para os programas de mestrado profissional na área de Ensino em Ciências e Matemática com o objetivo de identificar os produtos desenvolvidos nos programas de pós-graduação stricto sensu, modalidade mestrado profissional, na área de Ensino, tendo como foco principal ou como linha de pesquisa o Ensino de Matemática.

\section{Mestrado profissional na área de Ensino}

A área de Ensino é a que aloca o maior número de programas de pós-graduação stricto sensu profissionais no Brasil (CAPES, 2015b). No artigo $O$ mestrado (profissional) em Ensino, escrito por Moreira (2004), na época representante da área de Ensino de Ciências e Matemática na Capes, já ficava evidente a adesão da área à política proposta e, em paralelo, intentava-se desnudar o ainda desconhecido mestrado profissional.

A argumentação empregada por Moreira (2004) para defender a proposta estava centrada na identificação de áreas perfeitamente amoldadas aos mestrados profissionais, para as quais a pós-graduação stricto sensu deveria contribuir a fim de que fossem efetivadas as transformações necessárias. As áreas identificadas foram: (i) formação de professores dos ensinos fundamental e médio que pudessem atuar como iniciadores e líderes nos processos de formação de grupos de trabalho e estudo, compostos por professores; (ii) formação de profissionais que pudessem atuar de forma adequada em desenvolvimento e implementação curricular, coordenação e orientação de grupos de trabalhos e nos diversos processos de avaliação próprios do sistema escolar; (iii) formação de docentes das disciplinas "de conteúdo" das licenciaturas nas áreas específicas, e (iv) formação de professores de ensino superior para disciplinas “de conteúdo" em cursos de graduação 
em instituições que não têm tradição de pesquisa ou para disciplinas básicas em instituições que enfatizam a pesquisa.

Os argumentos desenvolvidos nesta seção serão centrados em outro artigo, O mestrado profissional na área de Ensino de Ciências e Matemática: alguns esclarecimentos, assinado por Moreira e Nardi (2009). 0 artigo chama a atenção por ter como autores dois ex-representantes da área de Ensino de Ciências e Matemática (2002-2007 e 2008-2010). Mesmo os autores enfatizando que o artigo não pode ser considerado um documento oficial da área, a notoriedade dos autores e a imbricação do proposto com as políticas da Capes produzem, de certa maneira, a conotação refutada.

Passados quase dois triênios de avaliação dos programas de pós-graduação por parte da Capes (2004-2006 e 2007-2009), em um cenário já bastante distinto do existente em 2004, a justificação do artigo de Moreira e Nardi (2009) é pautada em problemas identificados na apreciação de novas propostas de programas na área, na avaliação trienal realizada em 2007 e em relatórios de visitas feitas aos programas em 2008 e 2009. Com esses dados empíricos, Moreira e Nardi (2009, p. 2) inferem que

[...] alguns dos mestrados profissionais em andamento apresentam problemas, por exemplo, de estrutura curricular, com relação à definição de produção técnica e até mesmo de identidade, enquanto que algumas das novas propostas os confundem com variantes dos mestrados acadêmicos ou até mesmo de cursos de especialização.

Passa a área, assim, a conviver com problemas de outra natureza. Os programas existentes foram de cinco, em 2004, para 30, em 2010 e, na avaliação trienal (2010-2012) divulgada em 2013, o número de programas saltou para 104 programas, sendo 21 com mestrado e doutorado, três apenas com doutorado, 20 apenas com mestrado e 60 com mestrado profissional.

O Quadro 1 sumariza as diretrizes apresentadas por Moreira e Nardi (2009), nesse cenário de expansão, para os mestrados profissionais em Ensino de Ciências e Matemática: 


\section{Quadro 1. Diretrizes para os mestrados profissionais em Ensino de Ciências e Matemática}

\begin{tabular}{|c|c|}
\hline Natureza & $\begin{array}{l}\text { Aberto para professores de Física, Química, Biologia, } \\
\text { Matemática e disciplinas afins. A estrutura curricular } \\
\text { deve contemplar disciplinas específicas, que atendam à } \\
\text { especificidade da área de formação e área de atuação do } \\
\text { mestrando, e disciplinas comuns a todos os mestrandos. }\end{array}$ \\
\hline Localização & $\begin{array}{l}\text { Poderá ser localizado em uma unidade acadêmica, faculda- } \\
\text { de, instituto ou pró-reitoria. Ainda não existem programas } \\
\text { interinstitucionais. }\end{array}$ \\
\hline População-alvo & $\begin{array}{l}\text { Prioritariamente professores em serviço. Existe a possibili- } \\
\text { dade de oferta para profissionais que atuem em contextos } \\
\text { não formais ou informais de ensino. }\end{array}$ \\
\hline Vagas & $\begin{array}{l}\text { Fundamentalmente determinadas pela capacidade de } \\
\text { orientação - até o limite de oito por orientador. }\end{array}$ \\
\hline Duração & Até 36 meses. \\
\hline Atividades didáticas & $\begin{array}{l}\text { Concentradas em um ou dois dias da semana e em perío- } \\
\text { dos de férias. O curso pode incluir atividades de ensino a } \\
\text { distância, mas deve, majoritariamente, ser presencial. Ainda } \\
\text { não existem programas a distância. }\end{array}$ \\
\hline Disciplinas de conteúdo & $\begin{array}{l}\text { De } 30 \% \text { a } 50 \% \text { da carga horária total do curso deve ser de } \\
\text { disciplinas obrigatórias de conteúdo de Ciências e Matemá- } \\
\text { tica. As disciplinas devem ter enfoque didático. }\end{array}$ \\
\hline $\begin{array}{l}\text { Disciplinas de natureza } \\
\text { pedagógica e episte- } \\
\text { mológica }\end{array}$ & $\begin{array}{l}\text { Não são de natureza didática. Devem enfocar a aprendiza- } \\
\text { gem, a natureza do conhecimento e as novas abordagens de } \\
\text { ensino, possibilitando inovação em sala de aula e reflexão } \\
\text { sobre o ensino. }\end{array}$ \\
\hline $\begin{array}{l}\text { Acompanhamento da } \\
\text { prática profissional }\end{array}$ & $\begin{array}{l}\text { Obrigatório. Serve para o orientador acompanhar in loco } \\
\text { a implementação da proposta que gerará o trabalho de } \\
\text { conclusão. }\end{array}$ \\
\hline $\begin{array}{l}\text { Trabalho de conclusão } \\
\text { de curso e o produto } \\
\text { educacional }\end{array}$ & $\begin{array}{l}\text { A dissertação deve ser o relato de uma experiência de im- } \\
\text { plementação de estratégias ou de produtos de natureza } \\
\text { educacional. O trabalho deve gerar obrigatoriamente um } \\
\text { produto educacional. A dissertação é sobre a geração e } \\
\text { a implementação do produto. O produto é uma produção } \\
\text { técnica indispensável para a conclusão do curso. }\end{array}$ \\
\hline Questão da pesquisa & $\begin{array}{l}\text { Foco na aplicação do conhecimento, ou seja, na pesquisa } \\
\text { aplicada. O trabalho de conclusão não deve ser pensado } \\
\text { como pesquisa. }\end{array}$ \\
\hline Corpo docente & $\begin{array}{l}\text { Deve incluir um número significativo de doutores em Ensino } \\
\text { de Ciências e Matemática }\end{array}$ \\
\hline Produção & $\begin{array}{l}\text { Ênfase na produção técnica, com um mínimo de produção } \\
\text { acadêmica. }\end{array}$ \\
\hline Avaliação & $\begin{array}{l}\text { Ênfase na produção técnica, com estrutura curricular que } \\
\text { contemple disciplinas "de conteúdo" e com acompanha- } \\
\text { mento da prática profissional e trabalho de conclusão que } \\
\text { gerem, obrigatoriamente, um produto educacional. }\end{array}$ \\
\hline
\end{tabular}




\begin{tabular}{|l|l|}
\hline Bolsas & $\begin{array}{l}\text { Poucos programas receberam bolsas, que foram divididas } \\
\text { em até três partes, como ajuda de custo, sem a exigência } \\
\text { de dedicação exclusiva ao curso. }\end{array}$ \\
\hline Doutorado & $\begin{array}{l}\text { O mestrado profissional tem caráter terminal, apesar de } \\
\text { possibilitar ao egresso candidatar-se ao doutorado. } 0 \\
\text { doutorado profissional ainda é uma ideia distante. }\end{array}$ \\
\hline
\end{tabular}

Fonte: elaboração dos autores (adaptado de Moreira e Nardi, 2010)

Entre os pontos apresentados, serão discutidos de forma mais atenta o trabalho de conclusão de curso e o produto educacional. A opção remete, ainda que perifericamente, à discussão do acompanhamento da prática profissional.

Nesse viés, segundo Moreira e Nardi (2009) afirmam, não devem ser confundidas com estágio supervisionado práticas pedagógicas da licenciatura ou estágio de docência, considerando que o mestrando na modalidade profissional preferencialmente deva estar em exercício, caracterizando a vinculação do local de trabalho com a proposta que gerará o trabalho de conclusão do mestrado profissional. 0 ambiente de trabalho, para o mestrando, deve ser o gerador das questões a serem estudadas, procurando, em última instância, melhorar a realidade a que o objeto está circunscrito.

Com efeito, espera-se do futuro mestre não apenas uma dissertação, trabalho característico dos mestrados acadêmicos, mas também um trabalho de conclusão e um produto educacional. Ao trabalho acadêmico, que deve ser o "[...] relato de uma experiência de implementação de estratégias ou produtos de natureza educacional, visando à melhoria do ensino em uma área específica de Ciências ou Matemática [...]" (MOREIRA; NARDI, 2009, p. 4), apesar de sua natureza distinta dos mestrados acadêmicos, também é dado o nome de dissertação.

Em termos práticos, na visão da área de Ensino de Ciências e Matemática,

O mestrando deve desenvolver, por exemplo, alguma estratégia de ensino, uma nova metodologia de ensino para determinados conteúdos, um aplicativo, um ambiente virtual, um texto; enfim, um processo ou produto de natureza educacional e implementá-lo em condições reais 
de sala de aula ou de espaços não formais ou informais de ensino, relatando resultados dessa experiência. No momento atual, particular atenção deve ser dada à atualização curricular e ao uso das tecnologias de comunicação e informação na educação básica; mas, independente disso, o trabalho de conclusão deve necessariamente gerar um produto educacional que possa ser disseminado, analisado e utilizado por outros professores (MOREIRA; NARDI, 2009, p. 4).

Nessa perspectiva, a dissertação deve, necessariamente, tratar da geração ou implementação do produto, o qual, segundo Moreira e Nardi (2009), precisa ter identidade própria. 0 produto concebido não deve ser um apêndice da dissertação, mas a dissertação. Adicionalmente, preconiza-se que o produto seja uma produção técnica indispensável para a conclusão do mestrado profissional na área de Ensino.

A proposição torna explícito o foco do mestrado profissional em Ensino, a aplicação do conhecimento, e não a sua produção. Circunscreve-se, assim, o mestrado profissional de ensino no âmbito da pesquisa aplicada. Para a consecução dessa proposta:

\footnotetext{
O mestrando deve aprender sobre pesquisa, deve ser familiarizado com artigos e periódicos de pesquisa, mas não precisa ter cursos de metodologia da pesquisa educacional e seu trabalho não deve ser pensado com uma pesquisa, mas sim como o relato de um projeto de desenvolvimento (MOREIRA; NARDI, 2009, p. 5).
}

Demarcada a posição da área de Ensino de Ciências e Matemática, é adequado o confronto desta com o aparato legal no ponto em que a discussão está centrada, a pesquisa. A principal referência, nessa direção, é a Portaria Normativa $n^{\circ}$ 7, de 22 de junho de 2009 (MEC, 2009). Um excerto dessa portaria normativa é particularmente importante para a discussão em tela. Trata-se do art. $3^{\circ}$, que fala das possibilidades do mestrado profissional. 0 teor do artigo é o seguinte:

art. $3^{\circ} \mathrm{O}$ mestrado profissional é definido como modalidade de formação pós-graduada stricto sensu que possibilita:

I - a capacitação de pessoal para a prática profissional avançada e transformadora de procedimentos e processos aplicados, por meio da incorporação do método científico, habilitando o profissional para atuar em atividades técnico-científicas e de inovação; 
Il - a formação de profissionais qualificados pela apropriação e aplicação do conhecimento embasado no rigor metodológico e nos fundamentos científicos;

III - a incorporação e atualização permanentes dos avanços da ciência e das tecnologias, bem como a capacitação para aplicar os mesmos, tendo como foco a gestão, a produção técnico-científica na pesquisa aplicada e a proposição de inovações e aperfeiçoamentos tecnológicos para a solução de problemas específicos (BRASIL, 2009, p. 117).

0 art. $3^{\circ}$, ainda que claramente limitado pela natureza aplicada da pesquisa, de forma indelével, circunscreve os programas de mestrado no campo científico. Elementos como o método científico, o rigor metodológico nos fundamentos científicos e a produção técnicocientífica na pesquisa aplicada, entre outros, são evidenciados e denotam o mencionado.

Essa circunscrição, em certa medida, ainda que apresente convergências, permite a inferência de que os elementos científicos propostos na portaria normativa são incongruentes com as propostas da área de Ensino de Ciências e Matemática. O elemento mais notório talvez esteja na afirmação de que os mestrados profissionais da área não devem produzir conhecimento. É importante ressaltar que a pesquisa aplicada não é uma modalidade inferior de pesquisa, os recursos requeridos exigem, na direção da produção de conhecimentos congruentes com a realidade, conforme definido na Portaria Normativa $n^{\circ} 7$, rigor metodológico nos fundamentos científicos. A perspectiva coloca em discussão outra questão, a diretiva de que os mestrados profissionais não devem ter cursos de Metodologia da Pesquisa (MEC, 2009).

Considerando o cenário de outras áreas, como a Educação, nas quais ficam evidentes as fragilidades dos trabalhos produzidos na pósgraduação (ALVEZ-MAZZOTTI, 2002), a questão que se apresenta é: a diretriz de não alocação de cursos de metodologia voltados à elaboração da pesquisa no escopo dos mestrados profissionais não é uma forma de precarização?

Em parte, a ideia equivocada de que o mestrado profissional é um mestrado "inferior" deve-se às simplificações de fundamentos. Moreira e Nardi (2009, p. 2) refutam a posição ao dizerem que o 
mestrado profissional "não é um mestrado mais simples; é diferente, isso sim". E é assim mesmo. Provavelmente, considerando seu formato e exigências, fazer um mestrado profissional é até mais difícil do que fazer um mestrado acadêmico, principalmente porque o pesquisador deve debruçar-se sobre um objeto no qual está envolvido.

As diretrizes propostas até 2009, na avaliação trienal seguinte, foram mantidas. Consta do relatório da área:

Como se destinam aos profissionais da educação básica, os Mestrados Profissionais da Área de Ensino geram produtos educacionais disponibilizados para uso em escolas públicas do país, além das dissertações e artigos derivados do relato descritivo e analítico destas experiências (CAPES, 2013, p. 3).

No relatório de 2013, na linha do que se discutiu nas avaliações trienais anteriores, destacou-se claramente que, apesar dos avanços dos mestrados profissionais nos indicadores de produção acadêmica e da volumosa produção técnica, os mestrados profissionais necessitam de métricas mais adequadas ao tipo de produção que geram. Assim, faz-se necessário um sistema mais amoldado à natureza desses programas para avaliar e qualificar a produção técnica dos programas profissionais. No triênio 2010-2012, os programas profissionais foram responsáveis por 3.708 produtos, dos quais 1.384 foram classificados como materiais educativos e 2.324 como outras produções (Quadro 2):

\section{Quadro 2. Produção técnica da área de Ensino feita pelos mestrados profissionais}

\begin{tabular}{|c|c|}
\hline Produção técnica & Quantitativo \\
\hline Desenvolvimento técnica & 6 (materiais educativos) \\
\hline Desenvolvimento material didático & 697 (materiais educativos) \\
\hline Desenvolvimento aplicativo & 17 (materiais educativos) \\
\hline Desenvolvimento produto & 67 (materiais educativos) \\
\hline Cursos curta duração & 597 (materiais educativos) \\
\hline Demais tipos & 1.056 (outras produções) \\
\hline Programa de rádio ou TV & 58 (outras produções) \\
\hline Serviços técnicos & 1.103 (outras produções) \\
\hline Editoria & 107 (outras produções) \\
\hline
\end{tabular}

Fonte: Capes (2015b). 
Em termos práticos, o problema da avaliação permanece. Mesmo sendo a ficha adotada para a avaliação dos programas distinta (Tabela 1), e as diferenças pequenas, majoritariamente a avaliação, de modo diferente do reivindicado pela área, ocorre por meio de indicadores acadêmicos.

Tabela 1. Comparação dos pesos dos diferentes quesitos para a avaliação de programas acadêmicos e profissionais na área de Ensino de Ciências e Matemática na avaliação trienal de 2013

\begin{tabular}{|c|c|c|}
\hline Quesito & Acadêmicos & Profissionais \\
\hline Proposta do programa & $0 \%$ & $0 \%$ \\
\hline Corpo docente & $15 \%$ & $15 \%$ \\
\hline Corpo discente & $35 \%$ & $30 \%$ \\
\hline Produção intelectual & $35 \%$ & $30 \%$ \\
\hline Inserção social & $15 \%$ & $25 \%$ \\
\hline
\end{tabular}

Fonte: Capes (2015b).

Atualmente, o número de programas profissionais subiu para 67. A relevância desses programas para um país ainda tão carente de educação é indiscutível, pois absolutamente necessários para uma verdadeira "Pátria Educadora". Não obstante isso, os problemas identificados em 2004 ainda permanecem.

\section{Metodologia}

O estudo, em razão do ponto de vista com que foi abordado o problema, caracteriza-se como quantitativo e, devido aos seus objetivos, exploratório. 0 corte temporal abrangeu o período de 2004 até meados de 2014.

Para a construção do corpus documental da pesquisa, foi levantado junto ao sítio da Capes na rede mundial de computadores, na Grande Área Multidisciplinar, os programas de pós-graduação stricto sensu que pertencem à área de avaliação Ensino, selecionando os programas que oferecem mestrado profissional que tenha como foco principal ou como linha de pesquisa o Ensino de Matemática. 
Na sequência, procedeu-se à análise de cada um dos programas identificados por meio de suas páginas eletrônicas. Buscou-se, para tanto, identificar a existência de orientação explícita para a concepção do produto educacional ou se os trabalhos foram desenvolvidos livremente.

Após isso, levantaram-se os produtos constantes nas páginas dos programas e foi feita a categorização. A categorização observou as modalidades de produtos educacionais previstas na Portaria $n^{\circ} 7$ (MEC, 2009). O Quadro 3 sumariza essa classificação:

\section{Quadro 3. Categorias em que se enquadram os produtos gerados na área de Ensino de Matemática}

\begin{tabular}{|l|l|}
\hline Ambiente virtual & $\begin{array}{l}\text { Abrange os trabalhos indicados como ambientes colaborativos, } \\
\text { páginas de web, portais ou sites. }\end{array}$ \\
\hline Audiobook & $\begin{array}{l}\text { Por se tratar de um produto diferenciado dos demais, será } \\
\text { considerado como categoria. }\end{array}$ \\
\hline Curso & $\begin{array}{l}\text { São considerados nesta categoria cursos de extensão, cursos } \\
\text { de capacitação e oficinas. }\end{array}$ \\
\hline E-book & $\begin{array}{l}\text { Incluem-se como e-bookprodutos de diferentes nomenclaturas, } \\
\text { tais como livros digitais e tutoriais. }\end{array}$ \\
\hline Jogo & Diferentes tipos de jogos são incluídos nesta categoria. \\
\hline Livro & $\begin{array}{l}\text { Fazem parte da categoria dos livros, além daqueles produtos } \\
\text { que levam este nome, livros didáticos, livros paradidáticos, } \\
\text { revistas, livretos ou pequenos livros. }\end{array}$ \\
\hline Manual & $\begin{array}{l}\text { Apesar dos nomes diferentes, alguns produtos se assemelham } \\
\text { em seu objetivo e na sua forma de organização. São } \\
\text { considerados manuais: cadernos, encartes, cartilhas, guias, } \\
\text { materiais para formação, programas de formação, módulos, } \\
\text { roteiros, scripts, apostilas e materiais didáticos. }\end{array}$ \\
\hline Materiais & $\begin{array}{l}\text { Materiais concretos de apoio pedagógico, como kitse materiais } \\
\text { didáticos. }\end{array}$ \\
\hline Metodologia & $\begin{array}{l}\text { Esta categoria considera produtos que apresentam novas } \\
\text { propostas de projetos ou propostas de ensino, que tenham } \\
\text { em seu nome a palavra “metodologia”, modelos e propostas } \\
\text { de ensino. }\end{array}$ \\
\hline OVA (Objeto Virtual \\
de Aprendizagem) & $\begin{array}{l}\text { Consideram-se aplicativos, ferramentas de informação, } \\
\text { objetos de aprendizagem, planilhas ativas, recursos midiáticos, } \\
\text { softwares, WebQuests e programas. }\end{array}$ \\
\hline Produção técnica & $\begin{array}{l}\text { Produções de cunho acadêmico, como artigos, relatórios, } \\
\text { produtos técnicos e documentários. }\end{array}$ \\
\hline Projetos & $\begin{array}{l}\text { Textos destinados a diferentes públicos, tais como textos } \\
\text { de apoio, textos didáticos, textos voltados a professores e } \\
\text { apresentações em PowerPoint. }\end{array}$ \\
Produtos nomeados como projetos. \\
\hline produal
\end{tabular}




\begin{tabular}{|l|l|}
\hline $\begin{array}{l}\text { Propostas de } \\
\text { atividades }\end{array}$ & $\begin{array}{l}\text { Produtos que se referem a coletâneas, bancos, catálogos, } \\
\text { conjuntos, sugestões, propostas, sessões, encartes ou } \\
\text { sequências de atividades; experiências; lições; listas; planos } \\
\text { de conteúdo; propostas de ensino, educacionais, pedagógicas, } \\
\text { de aula ou didáticas; recomendações; alternativas didáticas; } \\
\text { unidades de ensino; validação de sequência didática; sequências } \\
\text { didáticas. }\end{array}$ \\
\hline Vídeo & Consideram-se vídeos com conteúdo diferente. \\
\hline
\end{tabular}

Fonte: elaboração dos autores (2014).

Foi quantificada a produção e observado como os produtos são distribuídos percentualmente. Buscou-se, ainda, verificar em quais programas mais de $50 \%$ dos produtos são concentrados em uma ou duas categorias.

Ressalta-se que alguns produtos analisados não apresentaram um formato plausivel de identificação e, assim, foram classificados como "não identificados".

\section{Resultados e discussões}

O levantamento inicial realizado no sítio da Capes apontou a existência, até o ano de 2014, de 113 programas cadastrados na área de Ensino, dos quais 63 oferecem cursos de mestrado profissional. Desses programas, 24 têm como foco principal ou linha de pesquisa o Ensino de Matemática.

Na identificação dos diferentes tipos de produtos desenvolvidos por esses 24 programas, constatou-se a falta de acesso on-line ou a existência de páginas inativas em nove programas.

Desse modo, a análise foi realizada em 15 programas. Nos programas verificados, foram identificadas 412 produções, sendo 277 com acesso direto aos produtos e 107 por meio da descrição presente nas dissertações sobre seus respectivos produtos. Vinte e oito produções tiveram sua análise prejudicada por diversos fatores, tais como problemas técnicos do site, não disponibilidade dos produtos de dissertação ou disponibilidade apenas da dissertação, que, por sua vez, não apresentava em sua redação menção ao produto. 
A Tabela 2 apresenta o quantitativo de produtos para o Ensino de Matemática por programa e por ano de produção.

Tabela 2. Produção para o Ensino de Matemática por programa e por ano de produção

\begin{tabular}{|c|l|l|l|l|l|l|l|l|l|l|l|}
\hline $\begin{array}{c}\text { Código do } \\
\text { Programa }\end{array}$ & $\mathbf{2 0 0 4}$ & $\mathbf{2 0 0 5}$ & $\mathbf{2 0 0 6}$ & $\mathbf{2 0 0 7}$ & $\mathbf{2 0 0 8}$ & $\mathbf{2 0 0 9}$ & $\mathbf{2 0 1 0}$ & $\mathbf{2 0 1 1}$ & $\mathbf{2 0 1 2}$ & $\mathbf{2 0 1 3}$ & $\mathbf{2 0 1 4}$ \\
\hline MP01 & & & & & & & & & & 9 & \\
\hline MP02 & & & & & & & & 6 & 8 & 4 & \\
\hline MP03 & & & & & & & 15 & 18 & 11 & 17 & 1 \\
\hline MP04 & & & & & & 1 & 8 & 10 & 16 & 5 & \\
\hline MP05 & & & & & & & 20 & 10 & 3 & & \\
\hline MP06 & & & & & 2 & & 8 & 7 & 9 & 4 & 1 \\
\hline MP07 & & & & & & & 2 & 4 & 2 & \\
\hline MP08 & & & & & & & & & 3 & 2 & \\
\hline MP09 & & & & & & 1 & 3 & 4 & 10 & 1 & \\
\hline MP10 & & & & & & & & 1 & & 1 & \\
\hline MP11 & & 1 & & & & 2 & 1 & 7 & 2 & 4 & \\
\hline MP12 & 3 & 3 & 4 & 4 & 6 & 1 & 3 & 11 & 9 & 8 & 2 \\
\hline MP13 & & & & & & & 3 & 2 & 1 & & \\
\hline MP14 & & & & 3 & 4 & 4 & 5 & 7 & 13 & 5 & 2 \\
\hline MP15 & & & & 7 & 7 & 8 & 9 & 6 & 17 & 10 & \\
\hline Total & $\mathbf{3}$ & $\mathbf{4}$ & $\mathbf{4}$ & $\mathbf{1 4}$ & $\mathbf{1 9}$ & $\mathbf{1 7}$ & $\mathbf{7 5}$ & $\mathbf{9 1}$ & $\mathbf{1 0 6}$ & $\mathbf{7 2}$ & $\mathbf{6}$ \\
\hline
\end{tabular}

Fonte: Capes (2015b).

Assim como Moreira e Nardi (2009) já apontavam em seu artigo O mestrado profissional na área de Ensino de Ciências e Matemática: alguns esclarecimentos, a produção dos mestrados profissionais é crescente. A tendência, porém, não se confirmou no ano de 2013, quando a quantidade de produções disponibilizadas foi menor do que nos três anos anteriores. Considerando o crescente número de programas na área, o que ocorreu em 2013 tendencialmente não deve acontecer novamente, e o vetor deve voltar a apontar crescimento.

Um dos motivadores desse fenômeno, observado durante a coleta de dados, pode ter sido não a baixa da produção científica, mas a falta de atualização de informações de alguns programas. Essa 
despreocupação com a publicação das produções científicas, de certa forma, pode prejudicar indiretamente o acesso à informação, seja para os docentes que poderiam ser beneficiados com os produtos gerados pelos programas de pós-graduação, seja para os pesquisadores, que podem até mesmo estar desenvolvendo pesquisas paralelas por falta de conhecimento do que já foi produzido.

Para visualizar a produção dos programas, desde o início de suas publicações até o período final da coleta de dados, no ano de 2014, apresenta-se na Tabela 3 a quantidade de produtos desenvolvidos para o Ensino de Matemática, organizados por programa e período de produção.

Tabela 3. Produtos desenvolvidos na área de Ensino de Matemática (por programa e período de produção)

\begin{tabular}{|c|c|c|}
\hline Código do programa & Período analisado & $\begin{array}{c}\text { Quantidade de produtos } \\
\text { desenvolvidos }\end{array}$ \\
\hline MP01 & 2013 & 9 \\
\hline MP02 & $2011-2013$ & 18 \\
\hline MP03 & $2010-2014$ & 62 \\
\hline MP04 & $2009-2013$ & 40 \\
\hline MP05 & $2010-2012$ & 33 \\
\hline MP06 & $2008-2014$ & 31 \\
\hline MP07 & $2010-2012$ & 8 \\
\hline MP08 & $2012-2013$ & 5 \\
\hline MP09 & $2009-2013$ & 19 \\
\hline MP10 & $2011-2013$ & 2 \\
\hline MP11 & $2005-2013$ & 17 \\
\hline MP12 & $2004-2014$ & 54 \\
\hline MP13 & $2010-2012$ & 6 \\
\hline MP14 & $2007-2014$ & 43 \\
\hline MP15 & $2007-2013$ & 64 \\
\hline
\end{tabular}

Fonte: pesquisa de campo (2014).

A partir da análise das produções e da categorização, conforme alocado no Quadro 3, apresentam-se na Tabela 4 os tipos de produtos 
para o Ensino de Matemática produzidos nos diversos cursos de mestrado profissional existentes no Brasil.

\section{Tabela 4. Categorias dos produtos}

\begin{tabular}{|c|c|}
\hline Categoria & Quantidade \\
\hline Ambiente virtual & 10 \\
\hline Audiobook & 1 \\
\hline Curso & 11 \\
\hline E-book & 7 \\
\hline Jogo & 4 \\
\hline Livro & 46 \\
\hline Manual & 88 \\
\hline Metodologia & 17 \\
\hline Produção técnica & 21 \\
\hline Produção textual & 10 \\
\hline Projeto & 1 \\
\hline Propostas de atividades & 145 \\
\hline Vídeos & 8 \\
\hline OVA & 19 \\
\hline Não identificados & 23 \\
\hline
\end{tabular}

Fonte: pesquisa de campo (2014)

Considerando as modalidades de produtos educacionais previstos na Portaria Normativa $n^{\circ} 7$, observa-se na Tabela 4 que os produtos adquirem tanto o formato físico quanto o virtual, visando atender às necessidades de uma sociedade marcada por desigualdades (MEC, 2009). Verifica-se, ainda, a ocorrência da ênfase aos produtos que visam desenvolver propostas de atividades que podem ser aplicadas em sala de aula e do desenvolvimento de manuais.

Segundo Moreira e Nardi (2009), as produções desenvolvidas nos mestrados profissionais, como, por exemplo, cadernos pedagógicos, textos de apoio e manuais didáticos, entre outros, devem gerar contribuições para o ensino.

Contudo, cabe uma reflexão acerca da qualidade dos produtos realizados, o que poderia ser um provável objeto de estudo para 
pesquisas futuras, uma vez que o enfoque do presente trabalho foi o levantamento das produções e como estas se categorizavam.

O enfoque na produção de propostas de atividades e de manuais é um ponto que chama a atenção. Isso pode estar ocorrendo por serem produções menos complexas, pois, em grande parte, tratam de uma produção escrita, relatando uma proposta de atividade organizada pelo acadêmico e aplicada durante sua pesquisa. Porém, salienta-se que esse tipo de produto em nada desmerece a qualidade do material elaborado, uma vez que tais produções provavelmente contribuem para o ensino da Matemática em suas diferentes etapas de formação.

Outro dado observado e apresentado na Tabela 5 foi o de que muitos programas desenvolvem uma mesma linha para a confecção de seus produtos. A Tabela 5 expõe as informações encontradas.

Tabela 5. Produtos desenvolvidos por categoria

\begin{tabular}{|c|c|c|c|c|c|c|c|c|c|c|c|c|c|c|c|c|}
\hline Categoria & $\begin{array}{c}\text { MP } \\
01\end{array}$ & $\begin{array}{c}\text { MP } \\
02\end{array}$ & $\begin{array}{c}\text { MP } \\
03\end{array}$ & $\begin{array}{c}\text { MP } \\
04\end{array}$ & $\begin{array}{c}\text { MP } \\
05\end{array}$ & $\begin{array}{c}\text { MP } \\
06\end{array}$ & $\begin{array}{l}\text { MP } \\
07\end{array}$ & $\begin{array}{c}\text { MP } \\
08\end{array}$ & $\begin{array}{c}\text { MP } \\
09\end{array}$ & $\begin{array}{c}\text { MP } \\
10\end{array}$ & $\begin{array}{c}\text { MP } \\
11\end{array}$ & $\begin{array}{c}\text { MP } \\
12\end{array}$ & $\begin{array}{c}\text { MP } \\
13\end{array}$ & $\begin{array}{c}\text { MP } \\
14\end{array}$ & $\begin{array}{c}\text { MP } \\
15\end{array}$ & TOTAL \\
\hline Ambiente virtual & 2 & 1 & & 2 & & & & & & & 2 & & & & 3 & 10 \\
\hline Audiobook & & & & & & & & 1 & & & & & & & & 1 \\
\hline Curso & & 3 & & & 1 & 1 & 2 & & & & 1 & & & 1 & 2 & 11 \\
\hline E-book & & & & & & & & & 1 & & & & & 5 & 1 & 7 \\
\hline Jogo & & 1 & & 1 & & & & & & & 1 & & & & & 4 \\
\hline Livro & 1 & & 35 & 3 & & 2 & & & 2 & & 1 & & & & 2 & 46 \\
\hline Manual & 5 & 1 & 7 & 16 & 2 & 17 & & 2 & 14 & & 6 & 8 & 4 & 2 & 5 & 89 \\
\hline Metodologia & & 1 & 3 & 1 & & & 2 & & & & & 6 & & 1 & 1 & 15 \\
\hline Produção técnica & & 2 & 1 & & 16 & & & & & & & 1 & & & 1 & 21 \\
\hline $\begin{array}{l}\text { Produção } \\
\text { textual }\end{array}$ & & 3 & & & & & & & 1 & 1 & & & & 4 & 1 & 10 \\
\hline Projeto & & & & & & 1 & & & & & & & & & & 1 \\
\hline $\begin{array}{c}\text { Propostas de } \\
\text { atividades }\end{array}$ & & 6 & 15 & 8 & 14 & 10 & & & 2 & 1 & 2 & 21 & 2 & 24 & 41 & 146 \\
\hline Vídeo & 1 & & & 2 & & & & & & & 1 & 1 & & & 2 & 7 \\
\hline OVA & & & & 5 & & & 4 & & & & 3 & & & 5 & 2 & 19 \\
\hline Não identificados & & & 3 & 2 & & & & 2 & & & & 16 & & & 3 & 24 \\
\hline
\end{tabular}

Fonte: pesquisa de campo (2014).

Verifica-se que os programas MP01 (55,56\% em uma única categoria), MP03 (56,45\% em uma única categoria), MP04 (60\% 
concentrados em duas categorias), MP05 (90,91\% concentrados em duas categorias), MP06 (54,84\% em uma única categoria), MP09 (73,68\% em uma única categoria), MP11 (52,94\% concentrados em duas categorias), MP12 (53,70\% concentrados em duas categorias), MP14 (57,14\% em uma única categoria) e MP15 (64,06\% em uma única categoria) adotam uma mesma linha para a orientação do desenvolvimento de seus produtos. Apenas o programa MP02 possui mais da metade de seus produtos distribuídos em mais de duas categorias. Porém, observou-se que $50 \%$ desses produtos se enquadram em duas categorias, o que mostra que sua linha de atuação é muito próxima à dos demais programas. Já os programas MP07, MP08, MP10 e MP13 não são passiveis de análise, pois são recentes, e sua produção ainda não possibilita tal verificação uma vez que seu total é inferior a 10 produtos publicados.

Essa gama de produção oferece diversos produtos educacionais que podem ser aplicados para o Ensino de Matemática, possibilitando ao professor conhecer e utilizar instrumentos diversificados de ensino, o que cumpre com o objetivo dos mestrados profissionais, que é o de contribuir com a sociedade por meio da produção acadêmica e técnica de forma diretamente aplicada. Porém, cabe salientar que, ao analisar as informações apresentadas, sete dos nove programas que intensificam suas produções em duas categorias focam a produção de manuais ou de propostas de atividades. Dessa forma, a posição pela não diversificação dos tipos de produtos produzidos pelos mestrados profissionais pode não estar diretamente ligada a sua proposta, pois apenas o MP03 expõe o fato de que o programa pretende a produção de livros para composição de coletâneas.

Apesar dessa observação, por meio das informações identificadas na presente pesquisa, considera-se que os programas têm buscado atender às premissas indicadas por Moreira e Nardi (2009, p. 4), de acordo com as quais o "trabalho de conclusão de curso deve, necessariamente, gerar um produto educacional que possa ser disseminado, analisado e utilizado por outros professores".

Assim, a característica peculiar do mestrado profissional de aliar à dissertação um ou mais produtos com especificações de uso é relevante 
para o espaço acadêmico e para o espaço social, pois segundo Scarano e Oliveira (2005), o mestre profissional deve estar apto para reconhecer e localizar a pesquisa baseado no debate acadêmico.

Ainda que fuja do escopo do presente estudo, uma questão que emergiu merece ser citada: esses produtos estão chegando para aqueles que deveriam ser os seus reais beneficiários? As dificuldades encontradas para levantar os dados da pesquisa, infelizmente, produzem indícios de que a resposta é não.

\section{Considerações finais}

Por meio da distribuição dos produtos em categorias, identificouse a concentração em três categorias de produtos educacionais: propostas de atividades, manual e livro. A pouca diversidade pode ser encarada como limitante para a área de Ensino de Matemática. A limitação obscurece uma gama de possibilidades que poderiam desenvolver e contribuir de diferentes formas com o meio educacional, seja em produções voltadas ao professor da área de Matemática, seja para o estudante dos diversos níveis e modalidades de educação.

A falta de manutenção das páginas de um número considerável de programas se mostrou um entrave para esta pesquisa e merece destaque. Como um dos princípios dos programas de mestrado profissional é a produção para a contribuição direta para o ensino, a falta de atualização faz com que alguns programas não cumpram integralmente com sua missão, considerando a propagação das pesquisas nacionalmente. Porém, cabe salientar que, pela não possibilidade de conhecer como os programas analisados estão inseridos em suas regiões, há a possibilidade de uso de outras estratégias de divulgação local de suas produções.

Ao mesmo tempo em que se reconhece que os produtos desenvolvidos nos programas de mestrado profissional da área de Ensino de Matemática são extremamente relevantes, considera-se que os programas poderiam passar a considerar outras possibilidades de 
produtos educacionais e desenvolver estratégias mais consistentes de difusão do que foi produzido.

Recebido em 28/03/2015

Aprovado em 11/08/2015

\section{Referências}

BRASIL. Lei n 13.005, de 25 de junho de 2014. Aprova o Plano Nacional de Educação - PNE e dá outras providencias. Diário Oficial [da] República Federativa do Brasil, Poder Executivo, Brasília, DF, 26 jun. 2014.

Ministério da Educação. Portaria Normativa $n^{\circ}$ 7, de 22 de junho de 2009. Dispõe sobre o mestrado profissional no âmbito da Fundação Coordenação de Aperfeiçoamento de Pessoal de Nivel Superior - Capes. Diário Oficial [da] República Federativa do Brasil, Brasília, DF, 23 jun. 2009. Seção 1, p. 117.

CAPES - Coordenação de Aperfeiçoamento de Pessoal de Nivel Superior. Formação de professores da Educação Básica. Disponível em: <http:/ / www.capes.gov.br/educacao-basica>. Acesso em: 26 jul. 2015a.

Páginas das áreas. Disponível em: <http:/ / www.capes.gov.br/ avaliacao/sobre-as-areas-de-avaliacao/paginas-das-areas>. Acesso em: 26 jul. 2015b.

Documento de Área 2013. Disponível em: <http:/ / www.capes. gov.br/images/stories/download/avaliacaotrienal/Docs_de_area/ Ensino_doc_area_e_comiss\%C3\%A3o_block.pdf>. Acesso em: 26 jul. 2015.

FISCHER, T. Mestrado profissional como prática acadêmica. RBPG, Brasília, v. 2, n. 4, p. 24-29, jul. 2005.

FREIRE, P. Pedagogia do Oprimido. 8. ed. São Paulo: Paz e Terra, 2005. 
MOREIRA, M. A. O mestrado (profissional) em ensino. RBPG, Brasília, n. 1, p. 131-142, jul. 2004.

MOREIRA, M. A.; NARDI, R. O mestrado profissional na área de Ensino de Ciências e Matemática: alguns esclarecimentos. Revista Brasileira de Ensino, Ciência e Tecnologia, v. 2, n. 3, set./nov. 2009.

RIBEIRO, R. J. O mestrado profissional na política atual da Capes. RBPG, Brasília, v. 2, n. 4, p. 8-15, jul. 2005.

SCARANO, F. R.; OLIVEIRA, P. E. A. M. Sobre a importância da criação de mestrados profissionais na área de ecologia meio ambiente. RBPG, Brasília, v. 2, n. 4, p. 90-96, jul. 2005. 